Natural Hazards and Earth System Sciences, 6, 89-96, 2006

SRef-ID: 1684-9981/nhess/2006-6-89

European Geosciences Union

(c) 2006 Author(s). This work is licensed

under a Creative Commons License.

\title{
Stability of saprolitic slopes: nature and role of field scale heterogeneities
}

\author{
A. Aydin \\ The University of Hong Kong, Department of Earth Sciences, Pokfulam Road, Hong Kong SAR, PR China
}

Received: 1 September 2005 - Revised: 5 December 2005 - Accepted: 5 December 2005 - Published: 17 January 2006

\begin{abstract}
Heterogeneities in various forms and scales often control the mechanisms and locations of failure and deformation, and the factor of safety of saprolitic slopes. This paper presents a critical review of field scale heterogeneities and their roles in controlling the stability of saprolitic slopes. In particular corestones and relict joints are analysed, with emphasis on characterization and possible instability modes. Abnormal flow patterns, fast build-up and/or chaotic distribution of pore water pressure are the most common causative factors of landslides. As heterogeneities are often responsible for the occurrence of such localized abnormalities, realistic models incorporating effects of these features can help predict how and where abnormal flow/pressure patterns may develop. Potential pitfalls during ground investigation in landslide prone slopes are elucidated and effective investigation strategies to avoid these pitfalls are recommended.

The uncertainties, for example, in distribution and volumetric percentage of corestones and in delineating zonal boundaries, require continuous upgrading of the engineering geological model during the construction stage of site investigations. Such uncertainties can be reduced in a cost-effective manner by recording drill penetration rates during installation of soil nails and horizontal drains. A better understanding of the interactions among the heterogeneities, the matrix and the engineering geological environment as a whole should enable the significance of discrete features in stability to be more consistently assessed, thereby providing a more rational basis for investigation and design practice in saprolitic profiles.
\end{abstract}

\section{Introduction}

The term saprolite refers to that part of the weathering profile where the soil largely preserves the microfabric and volume of its parent rock (Aydin et al., 2000). In humid climates,

Correspondence to: A. Aydin

(aaydin@hku.hk) saprolites often reach depths of tens of meters and generally have unusually heterogeneous internal structures and spatially variable boundaries. The uppermost section (generally less than $2 \mathrm{~m}$ ) of the soil over saprolites is considered as true or mature residual soils (or as lateritic soils). The mature and the saprolitic soils together are often referred to as (tropical) residual soils. As mappable and generally irregular upper part of weathered rock profiles, saprolite consists of materials dominantly decomposed to Grades IV and V (according to the six-fold weathering classification system). This definition of saprolite corresponds to the "saprolith" of Taylor and Eggleton (2001).

Heterogeneities in various forms and scales often control the mechanisms and locations of failure and deformation and the factor of safety of saprolitic slopes. Sources of heterogeneity in saprolitic profiles include: a) microfabric and mineralogical variations at the material scale (Aydin and Duzgoren-Aydin, 2002); and b) macrostructural features such as relict joints, relict veins, secondary clay seams, relatively less weathered intact rock slabs, irregular zones of contrasting weathering, differentially weathered dykes, corestones, and soil pipes at the field scale (Figs. 1 and 2). This large variability in type, abundance and scales of heterogeneities in saprolitic profiles means that critical features that control stability of slopes may go undetected during routine ground investigations.

Deere and Patton (1971) recommended that design based on stability calculations in saprolitic profiles should only be made in the full knowledge that slope failure could still occur, either because significant details were overlooked in the study or because the investigators were unable to anticipate the mode of failure and hence to apply the correct mode of analysis. Hencher et al. (1984) highlighted the importance of the heterogeneous nature of saprolitic slopes, noting that some steep slopes predicted to be unstable remained standing while others supposed to be stable collapsed or underwent large or progressive displacements. Based on a review of an extensive survey of saprolitic slopes in Hong Kong, Brand (1982) concluded that it was inappropriate to base design on 


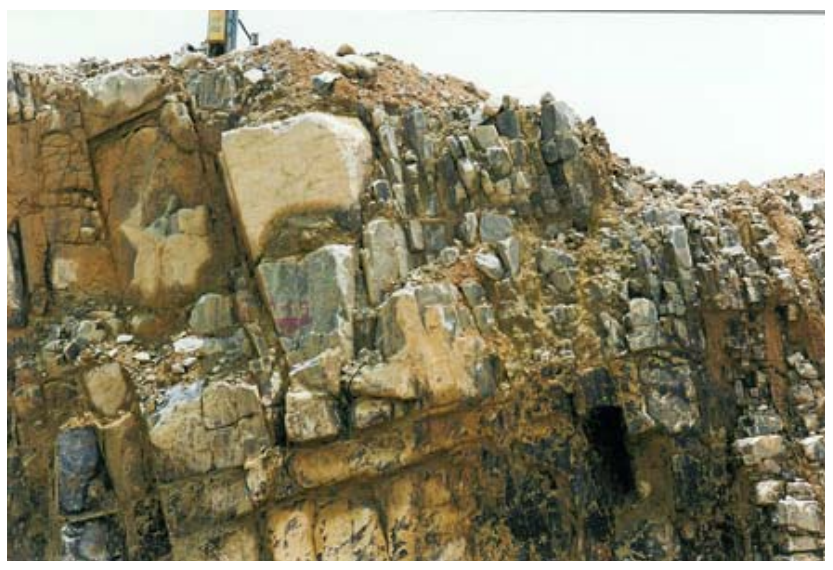

Fig. 1. Development of a saprolitic profile over volcanic (welded ash tuff) bedrock.

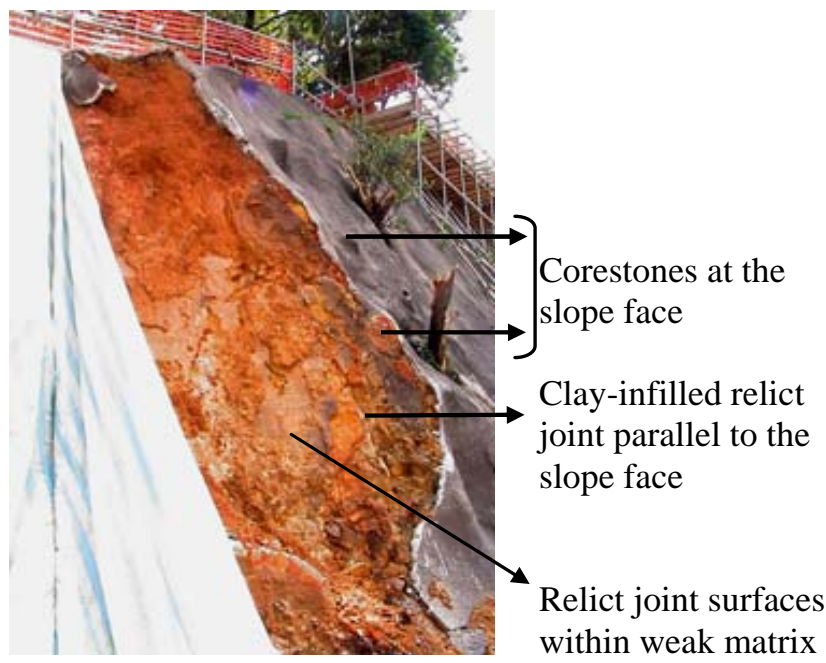

Fig. 2. A saprolitic profile cut normal to the slope face.

the behaviour of soil elements, and that the profile characteristics must be considered as a whole. Brand added that the rigorous application of engineering methods of analysis to provide design solutions was questionable, implying that design based on actual performance (precedent), back analysis and risk/hazard zoning (an engineering geological approach) is most fruitful. Similarly, Costa et al. (1989) indicated that macrostructural features in saprolitic soils were in many cases of greater importance for the behaviour of the soil mass.

This paper presents a critical review of the field scale heterogeneities, how their presence modifies mechani$\mathrm{cal} / \mathrm{hydraulic}$ behaviour and hence controls the stability of saprolitic slopes. Ground investigation methods and strategies to increase the likelihood of detecting and locating these heterogeneities in saprolites are examined. A preliminary study is presented to show how uncertainties can be reduced in a cost-effective manner by recording drill penetration rates during installation of soil nails and horizontal drains.

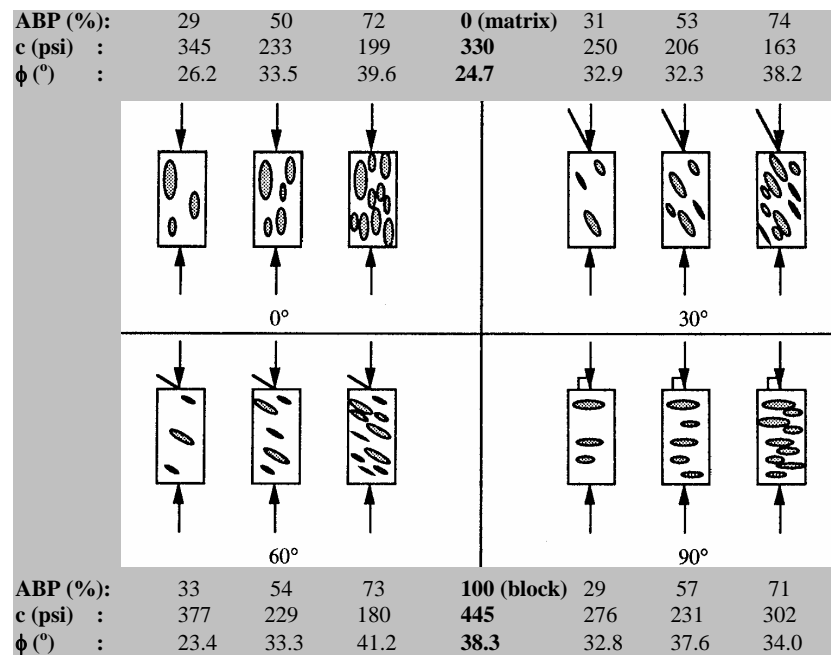

Fig. 3. Physical models designed to study influences of average block proportion (ABP) and block orientation (with respect to uniaxial loading direction) on cohesion (c) and internal friction angle ( $\phi$ ) (Lindquist and Goodman, 1994).

\section{Corestones}

A common form of heterogeneity defined by the chaotic occurrence of large particles (boulders and cobbles) in a matrix of considerably smaller particles (sand and silt) is typical of saprolites developed over widely to moderately jointed igneous and metamorphic rocks (Aydin et al., 2000). Due to the difficulties of sampling representative volumes of heterogeneous ground and the poor control of boundary conditions in the field experiments, physical model studies are most appropriate to study the effects of various factors both in isolation and in combined form. Lindquist and Goodman's model study (1994) found that (Fig. 3): a) increasing block proportion leads to a decrease in cohesion and an increase in internal friction angle and modulus of deformation; b) block orientation leads to anisotropy in strength (particularly cohesion component) and modulus; and c) there exists a threshold block proportion of $30 \%$ below which the presence of blocks has little effect on strength, confirming an earlier proposal by Hencher and Martin (1982). However, in saprolites, the potential presence of other features such as relict joints and heterogeneity of the intervening matrix material complicates such predictions.

The influence of large particles on stability and failure modes of colluvial slopes was examined by West et al. (1991). Depending on the relative strength and abundance of the larger particles, three types of potential failure surfaces are suggested (Fig. 4): 1) involving intrablock fractures (weak large blocks); 2) through block-matrix contacts (strong blocks; low stress allowing dilation); and 3) forming a wide shear zone due to the involvement of blocks (provided the blocks are not too large with respect to slope, the soil is not strongly bimodal, large particle content is $>25$ $30 \%$ or there is high stress suppressing dilation). However, 


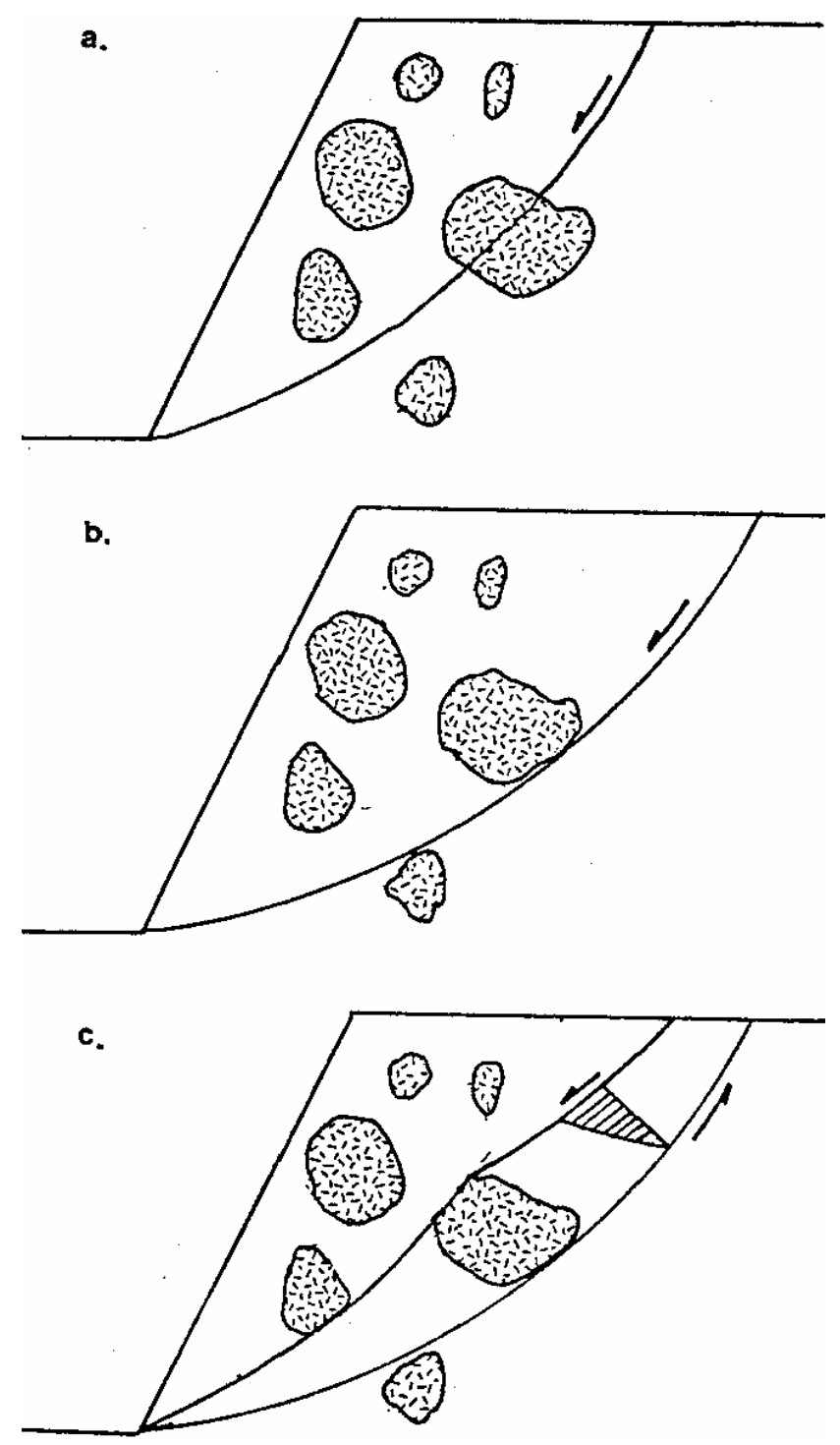

Fig. 4. Influence of large particles on the failure surface: (a) involving intrablock fracture; (b) through block-matrix contacts; and (c) forming a wide shear zone (West et al., 1991).

the physical model studies (Lindquist and Goodman, 1994) showed that failures tended to form along the block matrix contacts even if the blocks were only about twice as strong as the matrix in unconfined compression. The possibilities explored by West et al. (1991) do not account for the position and distribution of other features such as small relict discontinuities around which slip zones may initiate and propagate. Furthermore, the relative position and orientation of corestones with respect to the slope toe may significantly influence the critical local stress concentration and possibly the thickness and geometry of the potential slip zone.

Flintoff and Cowland (1982) suggested that many cut slopes in decomposed granites in Hong Kong stood at steep angles because of a favourable orientation of corestones close to the face. Conversely, on a steep face, a shallow soil cover developed over corestones can fail along the interface where

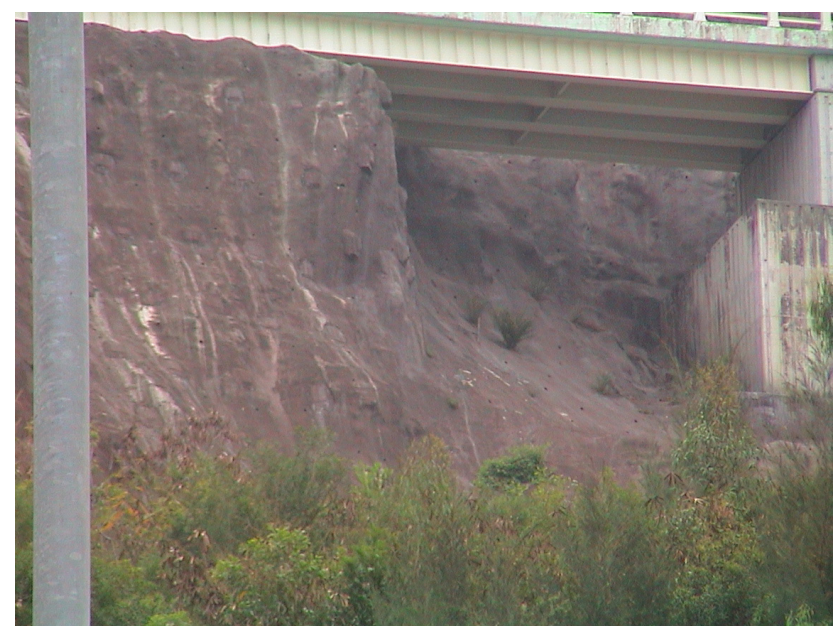

Fig. 5. A view from the shotcreted scar of a recent large-volume landslide within a saprolitic profile developed over pyroclastics (Shum Wan Road, Hong Kong). Note the projections of corestones on the nearly vertical surfaces forming the side and rear faces of the scar.

infiltrated water concentrates close to the face. Corestones often seen as projections on the high angle scars of landslides in saprolitic slopes prove the influence of their presence on defining the boundaries of failure (Fig. 5).

Penetrative weathering along fractures in the transition zone decreases shear strength and stiffness and increases the degree of freedom of blocks to rotate during deformation. Sandroni (1985) suggested that if remnant blocks are not in touch with one another and there exists a small thickness of residual soil between them, the mass will behave more like a soil in terms of shear strength and like a weak rock in terms of deformation. This assertion ignores the vital influence of relict joints on the behaviour of saprolitic slopes.

\section{Relict joints}

As microfabric features, macro-structural features such as joints inherited from the parent rock are preserved, particularly in igneous saprolites. Although these relict joints undergo a weakening process during weathering, their location, orientation, continuity and role as preferential weakness planes essentially remain unchanged. Main weatheringinduced changes in joint properties are mineralogical (wall alteration and filling/coating material) and geometrical (decrease in roughness and aperture through grain alteration and healing upon softening of asperities, increasing curvature of planes through creep and mass deformation). The detection, sampling and testing of relict joints therefore becomes increasingly difficult as material decomposition increases.

A large proportion of landslides in saprolites are associated with relict joints (St. John et al., 1969; Vargas and Pichler, 1957; Massad and Teixeira, 1985; Costa and Fernandes, 1985; Cowland and Carbray, 1988; Irfan and Woods, 1988; Chigira, 2001; Wen and Aydin, 2003). Fookes (1997) 


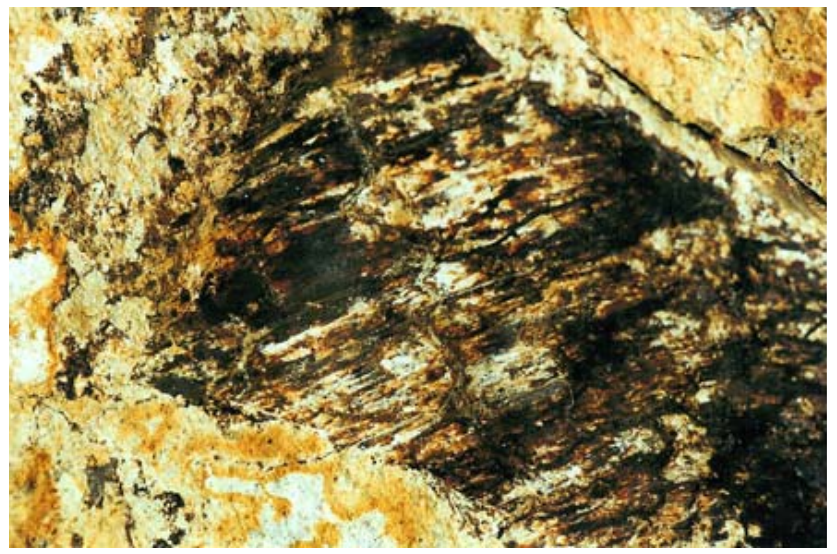

Fig. 6. Slickensided black seam on the surface of a relict joint plane.

suggested that relict joints represent a significant and uncertain hazard in the formation of temporary and permanent slopes. This is because relict joints are difficult to detect with the aid of routine site investigation procedures, and their potential occurrences are ignored until their control on mass shear strength becomes apparent by movements or failures along them (Deere and Patton, 1971; De Mello, 1972; Howat, 1985; Sandroni, 1985; Blight, 1989).

Relict joints often participate in slope failures as a combination of a near vertical release surface and an extensive basal slip plane. Complex failure surfaces may form when several discontinuities join or lie within a close distance. In the latter case, the intervening intact weathered rock blocks are sheared along certain segments of such surfaces. Often, toppling failures in saprolites is in the form of rotation of blocks within a creeping saprolitic mass. An increase in matrix-to-block proportions accelerates the rate of renewal of slope failure events.

Relict joints with black seams are common in saprolites (Figs. 6 and 7). Chemical analyses of black seams show that they generally contain fine-grained weathering products coated with Fe-Mn oxides and a humic substance leached from the upper horizons (St. John et al., 1969; Massad and Teixeira, 1985). Slickensides frequently observed on relict joints of this type are likely caused by repeated volumetric changes during saturation-drying cycles, particularly in sloping terrains where creep, gradual stress relief due to erosion and sudden removal of confining material during landslides can be expected. Relict joints with slickensided black seams have been found to have a much lower friction angle than other relict joints.

The likelihood that relict joints may form part of a potential failure surface depends on their geometrical distribution parameters, including their orientation, spacing and persistence. These also determine the likelihood of their intersecting with other joints and forming a network within saprolites. However, generally limited site data and possible changes in structural domains of nearby exposures and cuts require a sound structural framework of the area to be established to

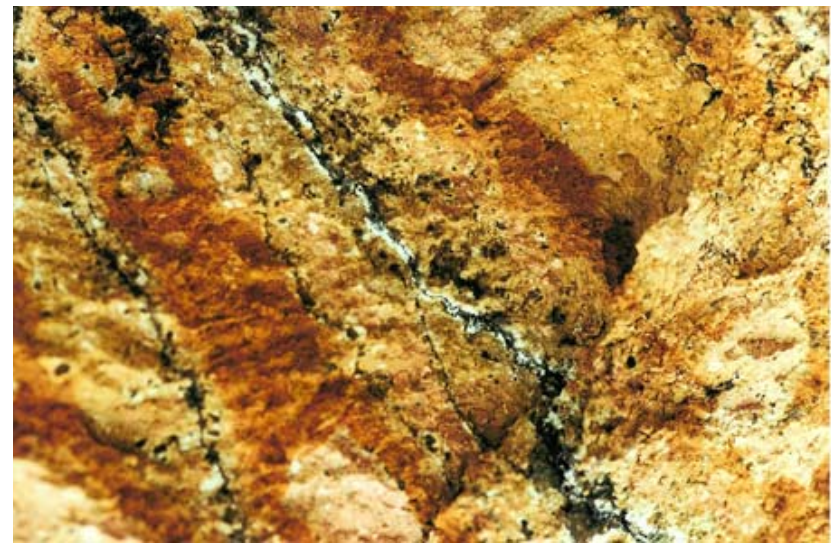

Fig. 7. Black seams sandwiched within a white clay vein formed along a deformed relict joint plane showing irregular waviness.

guide extrapolation and grouping of data into sets. The resulting distribution parameters can be used either in a probabilistic (Koo, 1982) or deterministic manner to assess the stability of slopes in saprolites developed over jointed rock masses.

\section{Heterogeneity regulating groundwater regime}

Relict joints, corestones, dykes and soil pipes regulate groundwater regimes and often dominate the field behaviour of saprolitic slopes. Sudden increases and gradual (delayed) decreases (asymmetric responses of saturation-dissipation curves) can be attributed to these features, which are interconnected or open to surface infiltration paths but terminate at low permeability boundaries. The prolonged state of saturation leads to loss of cohesion (relict bonding) and collapse of the material, as in shallow landslides and joint controlled failures. Remarkably different piezometric levels in closely spaced boreholes and irregular distributions and variable seepage rates observed in horizontal drains in cut slopes (Fig. 8) and (repaired) landslide scars testify to the complexity of groundwater storage and percolation patterns in saprolitic profiles.

From back-analyses of 11 slope failures, Hencher et al. (1984) concluded that for weathered profiles, many failures can be attributed to complex hydrogeological conditions that cannot generally be accounted for in stability analysis. Cowland and Carbray (1988) reported the failure of a slope cut into volcanic saprolite where significant seepages of groundwater were observed around some of the corestones in the landslide scar. Another form of field scale heterogeneity frequently found in igneous saprolites is a dyke of a different lithology and mass structure, resulting in significantly different zones of weathering within the host saprolites. These features influence stability either by producing a build-up of water pressures behind the slope (Au, 1986) or by providing localized flow zones depending on their dip and permeability. Weathering tends to form zones of materials 
with different permeabilities, which are aligned parallel to natural surfaces. For example, lower permeability layers over higher permeability zones parallel to a slope can result in the development of artesian or excess pore-water pressures in weathered slopes that may precede a slope failure (Deere and Patton, 1971).

Soil pipes are often centred in the head scarps of small shallow landslides. From Hele-Shaw simulation of flow potentials around a soil pipe parallel to an inclined slope, Pierson (1983) suggested that the highest-pressure build-up may develop some distance downhill. This indicates that such pipes may not always expose on the failure surface unless subsequent failures cut deeper into the slope. Relict joints and corestone-matrix boundaries may act as preferential seepage paths, sometimes resulting in high inflow rates leading to internal erosion and soil pipes (Brand et al., 1986) or in local pressure build-up at narrow conduits leading to removal of loose material and widening of the local aperture.

Raj (1998) reported a landslide along a relict fault plane where failure was attributed to the triggering role of ground vibrations caused by three large capacity trucks passing at the time of failure. However, an unusually long, dry period of 27 days prior to 29 days of continuous wet period was also noted as a preparatory factor. A relict fault is assumed to have acted as an impermeable barrier over which a perched water table would develop. However, it is clear that other cut slopes in the area received similar amounts of rainfall, and this casts doubt on Raj's claim that the failure of this slope was due to loss of matric suction. Other site-specific failure mechanisms might have operated. For example, as the relict fault did not daylight on the cut-slope face, the strength of the weathered rock-bridge between the slope face and the fault plane was critical to the stability of the slope. A progressive weakening of this bridge could have taken place, as this was the first failure since the excavation and occurred 5.7 years afterwards. Another possible mechanism is local shear failure within this highly pre-stressed bridge, as the slope had previously experienced a dry period followed by full saturation (Aydin and Egeli, 2001).

As primary joint sets in igneous saprolites are often subvertical, the damming effect of infilled subvertical relict joints may be extremely important in slope hydrogeology modelling and in the design of horizontal drains for pore water pressure relief. Transient water pressure-build up behind such joints and the confinement of infiltration and seepage pattern within isolated compartments leads to vertical groundwater movement and anomalous piezometric readings immediately after rainfalls. The length and frequency of horizontal drains (Fig. 8) should be selected to intercept such isolated compartments within a critical zone behind the slope face.

\section{Ground investigation in saprolites}

Variability in thickness and distribution of the boundaries of "uniform mixtures" of materials (i.e. zonal boundaries) are

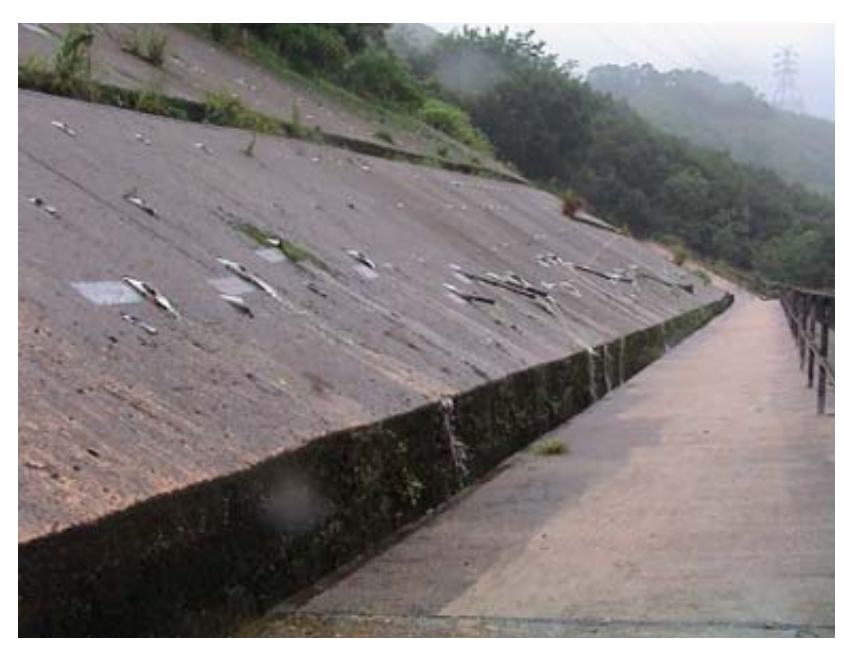

Fig. 8. A multiberm high slope with regular rows of raking and horizontal drains. Note the irregular flows pattern (Tsing Tsui Estate, HK).

one of the most common forms of heterogeneity in weathered profiles. De Mello (1972) suggested that after establishing the variability at scales of tens of meters it was necessary to reduce this scale to 1 to $2 \mathrm{~m}$, and finally to tens of centimetres within representative samples. This strategy addresses the problem of multilevel complex heterogeneity problem in ground investigation. On the other hand, Hencher and McNicholl (1995) pointed out that it was often difficult to predict geotechnical conditions accurately, despite careful investigation, and that variability cannot usually be predicted from interpolation or extrapolation. As a result, ground investigations in saprolites should be planned with the aim of minimizing the chance of the presence of field scale heterogeneities if their influence on mass strength, deformability and permeability is to be taken into account in design. Deere and Patton (1971) also strongly recommended "slope design by modified precedent", a process which requires a detailed surface and limited subsurface exploration. Additional subsurface data to determine the unfavorable/favorable conditions not considered in the design could be gathered by careful observations during the construction stage by experienced personnel with full knowledge of the design assumptions.

Knowledge of general profile characteristics in different lithologies (Aydin et al., 2000) and sites parameters such as thickness of transition zone established from previous investigations provide guidance to assess the required depth of drilling to differentiate between corestones and the bedrock. For example, in Hong Kong granites, the starting depth of a $5 \mathrm{~m}$ continuous core of Grade II-I material is assumed to represent the bedrock, whereas in volcanics a core of more than $10 \mathrm{~m}$ is necessary to prove the bedrock (Forth and Platt-Higgins, 1981). GCO (1987) suggested drilling for at least $5 \mathrm{~m}$ in Grade I to III material to confirm weathering front (bedrock). Corestones in boreholes are defined as sections of Grade I to III materials separated by at least $1 \mathrm{~m}$ of more weathered rock, whereas thinner $(<1 \mathrm{~m})$ zones 


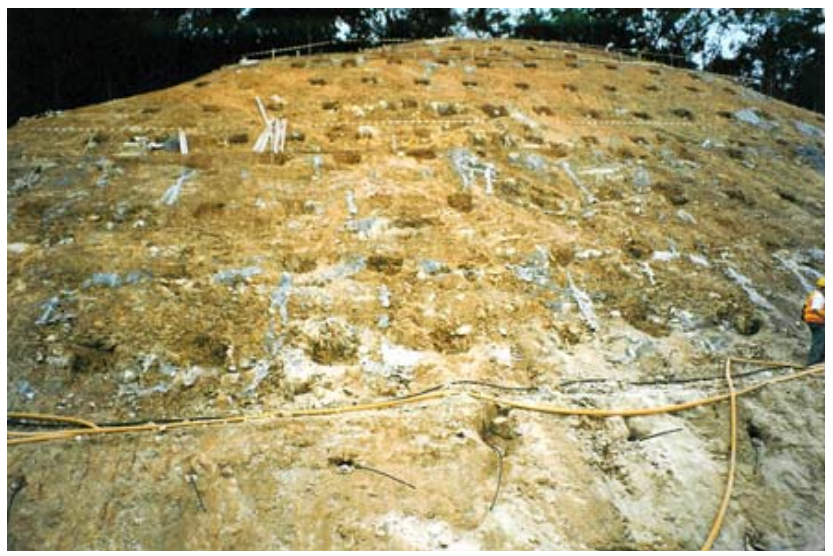

Fig. 9. Soil nails installed over a regular grid pattern of boreholes drilled throughout a volcanic saprolite profile.

are considered as widened joints (Shaw, 1997). However, this definition is not appropriate for the characterization of rock/soil masses, in which very thin weakness zones may dominate deformation and failure.

Geophysical methods such as seismic refraction are potentially useful for detecting overall (large-scale) variations in bedrock level. However, seismic refraction is not sensitive to site-scale lateral and vertical variations such as deep weathering pockets, alternating bands of weathered and unweathered materials, and zones of partially weathered material above bedrock (Forth and Platt-Higgins, 1981). Deere and Patton (1971) suggested that surface geophysical methods such as seismic and electrical resistivity surveys can provide considerable assistance in delineating weathering profiles if interpreted with knowledge of typical weathering profiles and if borings are provided for calibrating the profiles. Down-hole geophysical methods such as gamma-gamma and neutron logging may be more helpful in locating zones of different densities and water content respectively in the transitional zone (Deere and Patton, 1971).

As drill coring is often an unsatisfactory method for detecting and fully characterizing joint parameters, many investigators prefer large-diameter boreholes, deep trenches and hand-dug trial pits to establish the pattern of relict discontinuities (Deere and Patton, 1971; Sandroni, 1985). Recognition of the structural subdomain scales, heterogeneity levels and the variability within and between these domains should facilitate identification and characterization of relict joints within saprolites. This requires a comprehensive study that relates regional geological processes such as tectonics, emplacement, cooling and unloading to the formation and inherited evolution of ubiquitous joint patterns at site scales.

Patton (1984) emphasized the importance of accurate piezometric measurements in slope stability analysis and pointed out that piezometric readings are affected mainly by the length of completion zones and by the quality of the packers or seals. He suggested the use of modular piezometers by which a complete record of piezometric pressure distri- bution within short multiple intervals along a borehole can be obtained. Piezometric profiling is especially important in saprolitic slopes where heterogeneities regulate groundwater regimes. To determine the influence of heterogeneities on contaminant transport in saprolites, Corley et al. (1999) employed a multi-level sampler to obtain a continuous record of the relative distribution of hydraulic conductivity. They found that particularly vertical structures such as relict joints, veins and dykes missed during drilling had a significant influence on the plume geometry and could be detected by continuous profiling. This approach could also be used in locating and assessing the efficiency of horizontal drains in slopes cut into saprolitic profiles.

It is obvious that in-situ tests and field instrumentation are not easy to locate, carry out and interpret in heterogeneous ground. Nevertheless, significant advances in field characterization and testing were reported in a recent study (Anon., 1999). The high level of uncertainty that remains even after a careful and thorough ground investigation means that the engineering geological model of the ground may not accurately represent the critical features. Furthermore, important features in slope stability of saprolitic profiles such as zonal boundaries of weathering and a volumetric percentage of corestones in each zone are extremely difficult to predict from routine ground investigations. This uncertainty necessitates a continuous upgrading of the model during the construction stage of site investigation. This means an additional cost that is often difficult to justify in routine ground investigations. However, in most steep cut-slopes in saprolitic profiles, particularly in urban settings, extensive drilling is carried out for purposes of installing soil nails (Fig. 9) and horizontal drains (Fig. 8). Accurate penetration rate records of non-coring pneumatic percussive drilling (Fig. 10) calibrated against various drilling parameters will provide valuable additional data in a very cost-effective way, enabling engineering geological models to be updated during the construction stage. This approach complements the mixed design practice recommended by Deere and Patton (1971).

A preliminary study was carried out under the supervision of the author to demonstrate the use of penetration rate records to help improve predictions of subsurface conditions within saprolitic slopes in Hong Kong (Lam, 2000). A total of 24 drill penetration rate records were obtained at four cut slopes for which reasonably good control of ground conditions were available from the site investigation drillholes. The depth vs. cumulative drill time curves such as shown in Fig. 11 suggested that even minor variations in the ground conditions can be interpreted especially when a complete set of drilling parameters are recorded simultaneously.

\section{Conclusions}

- In saprolites, potential presence of features such as relict joints and heterogeneity of the intervening matrix material complicates attempts to predict the influence of 


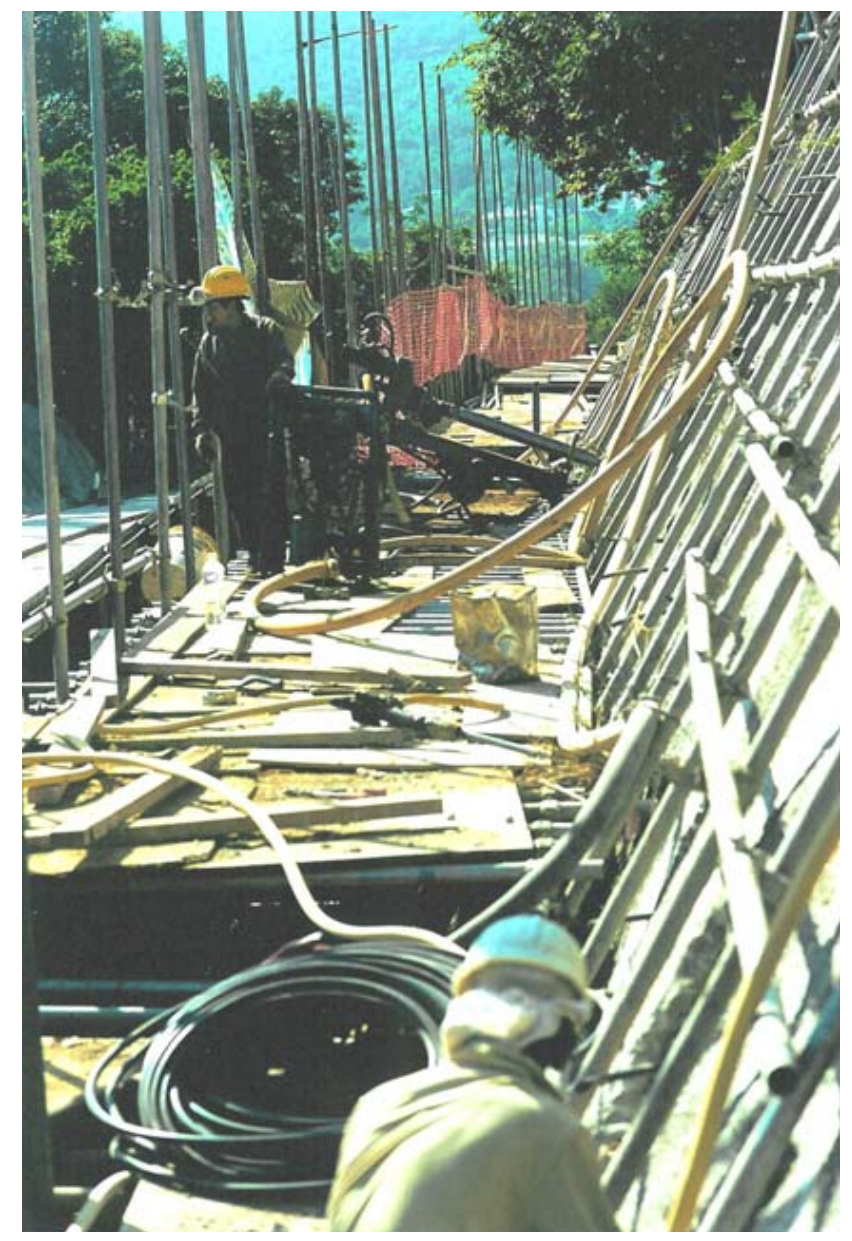

Fig. 10. A pneumatic rotary-percussive drill machine on a temporary platform set-up for the installation of soil nails and horizontal drains along a predefined series of rows.

corestones on the mass shear strength, modulus and threshold block proportions.

- Although relict joints undergo a weakening process during weathering, their location, orientation, continuity and their role as a preferential weakness planes essentially remain unchanged. This means that ground investigation resources should be devoted to the detection and characterization of joints rather than to expensive "undisturbed" sampling and testing for matrix properties.

- The damming effect of infilled subvertical relict joints in igneous saprolites may be extremely important in slope hydrogeology modelling and in design of horizontal drains for pore water pressure relief. Transient pore water pressure build-up behind such joints and confinement of infiltration and seepage pattern within isolated compartments leads to vertical groundwater movement and anomalous piezometric readings immediately after rainfalls. The limited open length and diameter of

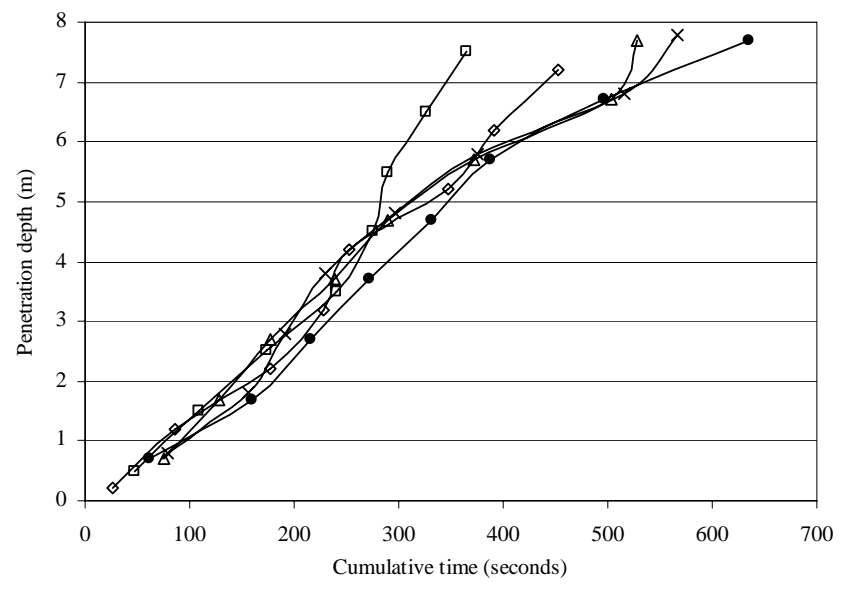

Fig. 11. Penetration depth vs. cumulative time curves from pneumatic drilling records in a saprolitic slope (7SE-D/C246) developed over pyroclastic rocks in Hong Kong (data from Lam, 2000). Note significant variations in penetration rate patterns along and among very closely spaced drillholes implying various forms of heterogeneities resisting (e.g. corestones, slabs, vegetation roots) or facilitating penetration (e.g. preferentially weakened - fractured and/or leached - zones, soil pipes).

drains may be inappropriate to deal with such vertical and isolated compartment flow patterns.

- In view of the multilevel complex heterogeneity in saprolites, ground investigations should be planned with the sole aim of minimizing the chance of the presence of field scale heterogeneities. The inevitable uncertainties require a continuous upgrading of the engineering geological model during the construction stage of the site investigation, and the remaining uncertainties can be reduced in a cost-effective manner by the use of accurate penetration rate records. This data, where available, presents a valuable opportunity for the modification of slope design.

- Continuous profiling of pore pressure, flow rate and tracer distributions along boreholes is potentially useful for characterizing the heterogeneities in saprolites, particularly in detecting subvertical features. These measurements could also be used in locating and assessing the efficiency of horizontal drains in cut-slopes.

- Slip zones rarely develop entirely within the confines of the matrix. Heterogeneities often take part directly in forming the slip surface. Models based on matrix behaviour would generally give upper or lower bound solutions depending on the contribution of heterogeneities to shear resistance. Slip zones are also affected indirectly by heterogeneities through their influence on groundwater regimes. Thus, the concept of locating critical slip surfaces has a limited use in heterogeneous soils in which both deformation and failure are controlled by discrete features. 
Acknowledgements. This study was supported by a grant from the Research Grants Council of the Hong Kong Special Administrative Region, China (Project No. HKU 7002/03P).

Edited by: M. Parise

Reviewed by: two referees

\section{References}

Anon.: Behavioral characteristics of residual soils. Geotechnical Special Publication No. 92, American Society of Civil Eng., 1999.

Au, S. W. C.: Decomposed dolerite dykes as a cause of slope failure, Hong Kong Engineer, 2, 14, 33-36, 1986.

Aydin, A., Duzgoren-Aydin, N. S., and Malpas, J.: A review of igneous and metamorphic saprolites, Journal of Nepal Geological Society, 22, 11-16, 2000.

Aydin, A. and Egeli, I.: Stability of slopes cut in metasedimentary saprolites in Hong Kong, Bull. Eng. Geol. Env., 60, 315-319, 2001.

Aydin, A. and Duzgoren-Aydin, N. S.: Indices in scaling and predicting weathering-induced changes in rock properties, Environmental and Engineering Geoscience, VIII, 2, 121-135, 2002.

Blight, G. E.: Design assessment of saprolites and laterites, Proc. 12th Int Conf SMFE, 4, 2477-2484, 1989.

Brand, E. W.: Analysis and design in residual soils, Proc. ASCE Conf on Engineering and Construction in Tropical and Residual Soils, 89-143, 1982.

Brand, E. W., Dale, M. J., and Nash, J. M.: Soil pipes and slope stability in Hong Kong, Quarterly J. Engineering Geology, 19, 301-303, 1986.

Corley, H. P., Martin, R. L., and Macklin, R. L.: Characterization of saprolite heterogeneities using innovative techniques. Geotechnical Special Publication No. 92, American Society of Civil Eng., 64-76, 1999.

Chigira, M.: Mirco-sheeting of granite and its relationship with landsliding specifically after the heavy rainstorm in June 1999, Hiroshima Prefecture, Japan, Engineering Geology, 59, 219231,2001

Costa, A. J. and Fernandes, C. E. M.: Slides in saprolites from gneissic rocks with relict slip surfaces, the B.N.E.D.E.S. case history, Proc. 1st Int. Conf. on Tropical Lateritic and Saprolitic Soils, 2, 49-55, 1985.

Costa, L. M., Dobereiner, L., de Campos, T. M. P., and Vargas, E.: Fabric and engineering properties of saprolites and laterites, Proc. 12th Int. Conf. SMFE, 4, 2763-2476, 1989.

Cowland, J. W. and Carbray, A. M.: Three cut slope failures on relict discontinuities in saprolitic soils, Proc. 2nd Int. Conf. on Geomechanics in Tropical Soils, 1, 253-258, 1988.

De Mello, V. F. B.: Thoughts on soil engineering applicable to residual soils, Proc. 3rd Southeast Asian Conf. on Soil Engineering, 5-34, 1972.

Deere, D. U. and Patton, F. D.: Slope stability in residual soils, Fourth Panam. Conf. SMFE, San Juan, Puerto Rico, 1, 87-170, 1971.

Flintoff, W. T. and Cowland, J. W.: Excavation design in residual soil slopes, Proc. ASCE Conf on Engineering and Construction in Tropical and Residual Soils, 539-556, 1982.
Fookes, P. G. (Ed.): Tropical residual soils: Geological Society Engineering Group Working Party Revised Report, The Geological Society, London, 1997.

Forth, R. A. and Platt-Higgins, P. M.: Methods of investigation of weathered rocks in Hong Kong, Proc. Int. Symp. on Weak Rock, 519-526, 1981.

GCO: Guide to site investigation (Geoguide 2), Geotechnical Control Office, Hong Kong SAR, 1987.

Hencher, S. R. and Martin, R. P.: The description and classification of weathered rocks in Hong Kong for engineering purposes, Proc. 7th Southeast Asian Geotechnical Conf., 125-142, 1982.

Hencher, S. R. and McNicholl, D. P.: Engineering in weathered rock, Quarterly J. Engineering Geology, 28, 253-266, 1995.

Hencher, S. R., Massey, J. B., and Brand, E. W.: Application of back-analysis to some Hong Kong landslides, Proc. 4th Int. Symp. on Landslides, 631-638, 1984.

Howatt, M. D.: Completely weathered granite-soil or rock?, Quart J. Engineering Geology, 18, 199-206, 1985.

Irfan, T. Y. and Woods, N. W.: The influence of relict discontinuities on slope stability in saprolitic soils, Proc. 2nd Int. Conf. on Geomechanics in Tropical Soils, 1, 267-276, 1988.

Koo, Y. C.: Relict joints in completely decomposed volcanics in Hong Kong, Canadian Geotechnical Journal, 19, 117-123, 1982.

Lam, K. M.: Implication and use of accurate drill progress rate measurements, Graduation Project, Department of Earth Sciences, The University of Hong Kong, 2000.

Lindquist, E. S. and Goodman, R. E.: Strength and deformation properties of a physical model melange, Proc. 1st NARM Symp, 843-850, 1994.

Massad, F. and Teixeira, H. R.: Deep cut on saprolitic soils conditioned by relict structures, Proc. 1st Int. Conf. on Tropical Lateritic and Saprolitic Soils, 2, 381-391, 1985.

Patton, F. D.: Climate, groundwater pressures and stability analyses of landslides, Proc. 4th Int. Symp. on Landslides, 43-59, 1984.

Pierson, T. C.: Soil pipes and slope stability, Quarterly J. Engineering Geology, 16, 1-11, 1983.

Raj, J. K.: The failure of a slope cut into the weathering profile developed over a porphyritic biotite granite, Journal of Asian Earth Sciences, 16, 4, 419-427, 1998

Sandroni, S. S.: Sampling and testing of residual soils in Brazil, in Sampling and Testing of Residual Soils, edited by: Brand, E. W. and Phillipson, H. B., Scorpion Press, Hong Kong, 31-50, 1985.

Shaw, R.: Variations in sub-tropical deep weathering profiles over the Kowloon Granite, Hong Kong, J. Geol. Soc., 154, 10771085, 1997.

St. John, B. J., Sowers, G. F., and Weavers, C. H. E.: Slickensides in residual soils and their engineering significance, Proc. 7th Int Conf. on SMFE, II, 591-597, 1969.

Vargas, M. and Pichler, E.: Residual soil and rock slides in Santos (Brazil), Proc. 4th Pan-American Conf on SMFE, 6/27, 394-398, 1957

Wen, B. P. and Aydin, A.: Microstructural study of a natural slip zone, quantification and deformation history, Engineering Geology, 68, 289-317, 2003.

West, L. J., Hencher, S. R., and Cousens, T. W.: Assessing the stability of slopes in heterogeneous soils, Proc. 6th Int. Symp. on Landslides, 591-595, 1991. 